\title{
An Integrated Three-phase Transformer for Partial Parallel Dual Active Bridge Converter
}

Huang, Jiasheng ; Zhang, Zhe; Xiao, Yudi; Sun, Bainan; Andersen, Michael A. E.

Published in:

Proceedings of 10th International Conference on Power Electronics

Publication date:

2020

Document Version

Peer reviewed version

Link back to DTU Orbit

Citation (APA):

Huang, J., Zhang, Z., Xiao, Y., Sun, B., \& Andersen, M. A. E. (2020). An Integrated Three-phase Transformer for Partial Parallel Dual Active Bridge Converter. In Proceedings of 10th International Conference on Power Electronics [8797262] IEEE.

\section{General rights}

Copyright and moral rights for the publications made accessible in the public portal are retained by the authors and/or other copyright owners and it is a condition of accessing publications that users recognise and abide by the legal requirements associated with these rights.

- Users may download and print one copy of any publication from the public portal for the purpose of private study or research.

- You may not further distribute the material or use it for any profit-making activity or commercial gain

- You may freely distribute the URL identifying the publication in the public portal 


\title{
An Integrated Three-phase Transformer for Par- tial Parallel Dual Active Bridge Converter
}

\author{
Jiasheng Huang ${ }^{1}$, Zhe Zhang ${ }^{2}$, Yudi Xiao' ${ }^{2}$, Bainan $\mathrm{Sun}^{2}$, and Michael A.E. Andersen ${ }^{2}$ \\ ${ }^{1}$ School of Electrical Engineering, Xi'an Jiaotong University, Xi'an, China \\ ${ }^{2}$ Department of Electrical Engineering Technical University of Denmark Kgs, Lyngby, 2800 Denmark
}

\begin{abstract}
In this paper, an integrated three-phase transformer is utilized in the partial parallel dual active bridge (PPDAB) converter. Due to the symmetrical structure, the flux generated by the primary windings is equally distributed to the three outer legs. Given the same number of turns of the windings in each parallel modules, the ac currents can inherently balance in the parallel modules. In order to enlarge the leakage inductor to serve as the interfacing ac inductor in the PPDAB converter, the coupling between the primary windings and secondary windings is weakened by placing the primary and secondary windings on the center and outer legs, respectively. Compared to the discrete three-phase transformers, the winding loss will also decrease with the proposed structure. A $1 \mathrm{~kW} 400 \mathrm{~V} / 50 \mathrm{~V} 500 \mathrm{kHz}$ prototype with an efficiency of $96.72 \%$ is built and tested to verify the theoretical analysis.
\end{abstract}

Index Terms-- DAB, dc-dc, integrated magnetics, threephase transformer

\section{INTRODUCTION}

Dual active bridge (DAB) converter is widely used in energy storage systems, automotive applications, smart transformers, etc., due to its attractive characteristics such as bidirectional power flow capability, symmetrical configuration and zero voltage switching (ZVS) [1]-[8].

In [6], an overview of the DAB converter for highfrequency-link power conversion systems was given.

In [7], a novel neutral point clamped (NPC) DAB converter with a blocking capacitor is proposed for energy storage systems. By inserting a blocking capacitor in the primary loop of the NPC DAB converter, the proposed topology adapts to wide output voltage range applications.

In [8], one DAB-based architecture, quadruple active bridge (QAB) converter is proposed to be used as a basic module of a modular three-stage solid-state transformer (SST) or smart transformer. A $20 \mathrm{~kW}$ prototype of the smart transformer was built to demonstrate the high potential of the QAB converter on efficiency and cost.

Achieving high power density is also emerging as a goal in power electronics applications. Passive components such as inductor, capacitor, and transformer often occupy the vast majority of the volume of the converter. Besides, increasing the switching frequency to reduce the size of passive components, integrated magnetics are also widely used in power electronic converters [9]-[15].

Moreover, integrated magnetic techniques are widely applied to high power applications.

In [14], a matrix transformer structure was proposed for a $1 \mathrm{MHz}, 380 \mathrm{~V} / 12 \mathrm{~V}, 800 \mathrm{~W}$ LLC converter. The concept

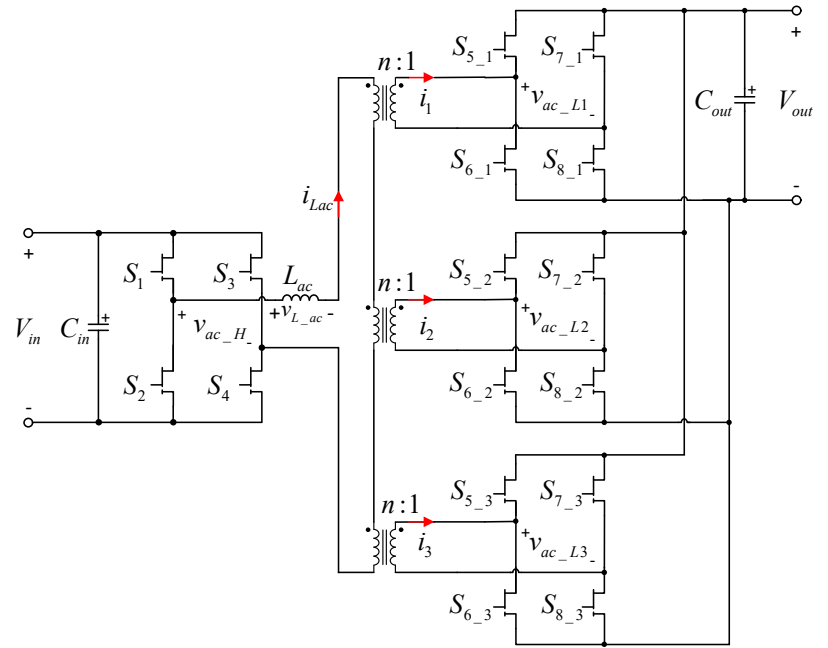

Fig. 1. Topology of the partial parallel dual active bridge converter

of flux cancelation is used to reduce core loss and core size.

In [15], a 6-layer PCB winding three-phase transformer is reported. The leakage inductor can be controlled to the desired value by adjusting the reluctance of the additional center post to serve as the resonant inductor. However, the additional center post will also increase the core loss.

In this paper, a new integrated three-phase transformer is proposed for the partial parallel dual active bridge (PPDAB) converter, shown in Fig. 1. The PPDAB converter was first proposed and researched in [4]. Based on the dual active bridge (DAB) topology, the transformer windings on the high-voltage(HV) side are connected in series; on the other hand, the full-bridges units on the lowvoltage (LV) side are connected in parallel, making the voltage gain and the transmission power significantly increased.

For the PPDAB converter, interfacing inductors are needed in the ac link in order to enable regulation of power flow between the HV and LV sides. Therefore, the proposed three-phase transformer integrates not only three transformers but also the ac inductor into one magnetic structure so that further reduces the size and volume of magnetic components. Moreover, the winding loss can be reduced accordingly with the proposed magnetic integration method. The symmetrical structure leads to the flux generated by the primary windings equally distributed to the three outer legs. Given the same number of turns of the windings in each parallel modules, the high-frequency ac currents are balanced on the LV side. 


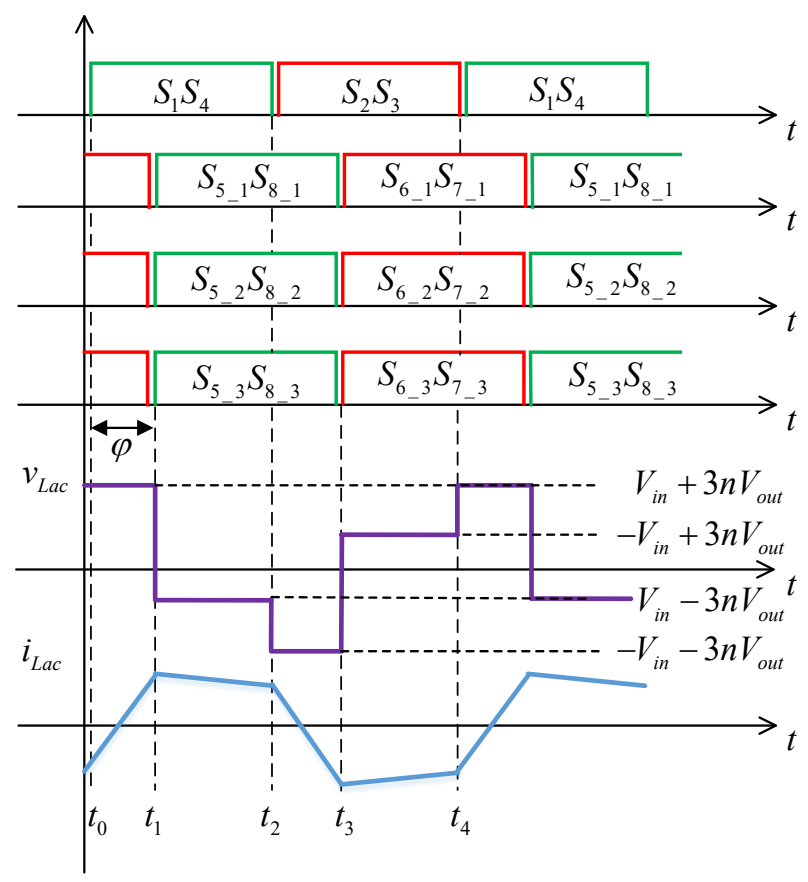

Fig. 2. Typical waveform of SPS control

This paper is organized as follows. After the introduction, Section II analyzes the operation of the PPDAB converter. Section III gives the detailed analysis on the magnetic integration of three-phase transformers and ac inductors, and compares it with the discrete threephase transformer, which is comprised of three sets of UI core. Section IV presents the experimental results on the $1 \mathrm{~kW}$ three-phase PPDAB converter to verify the converter's analysis and operation with the newly proposed integrated three-phase transformer. Finally, conclusion is given in Section V.

\section{Partial Parallel Dual Active Bridge DC/DC CONVERTER}

The typical waveforms of the PPDAB converter with single-phase-shift(SPS) control are shown in Fig. 2, where $\varphi$ represents the phase-shift angle as a percentage of the switching period $T_{s}, f_{s}$ is the switching frequency, and $L_{a c}$ is the total leakage inductance referred to the HV side. Moreover, the theoretical analysis below is based on the following assumptions: 1) All the switches are ideal. 2) The input voltage $V_{\text {in }}$ and output voltage $V_{\text {out }}$ are constant.

\section{$\left[\mathbf{t}_{\mathbf{0}}, \mathbf{t}_{1}\right]$}

In this subinterval, the voltage across the ac inductor is $V_{\text {in }}+3 n V_{\text {out }}$. The ac inductor current increases linearly.

$$
i_{L a c}\left(t_{1}\right)=i_{L a c}\left(t_{0}\right)+\frac{V_{\text {in }}+3 n V_{\text {out }}}{L_{a c}} \cdot \varphi T_{s}
$$

$\left[\mathbf{t}_{1}, \mathbf{t}_{2}\right]$

In this subinterval, the voltage across the ac inductor is $V_{\text {in }}-3 n V_{\text {out }}$.

$$
i_{\text {Lac }}\left(t_{2}\right)=i_{\text {Lac }}\left(t_{1}\right)+\frac{V_{\text {in }}-3 n V_{\text {out }}}{L_{a c}} \cdot\left(\frac{1}{2}-\varphi\right) T_{s}
$$

Similarly, $i_{L a c}\left(t_{3}\right)$ and $i_{\text {Lac }}\left(t_{4}\right)$ can be derived as expressed in (3) and (4),

$$
\begin{gathered}
i_{\text {Lac }}\left(t_{3}\right)=i_{\text {Lac }}\left(t_{2}\right)-\frac{V_{\text {in }}+3 n V_{\text {out }}}{L_{a c}} \cdot \varphi T_{s} \\
i_{\text {Lac }}\left(t_{4}\right)=i_{\text {Lac }}\left(t_{3}\right)+\frac{-V_{\text {in }}+3 n V_{\text {out }}}{L_{a c}} \cdot\left(\frac{1}{2}-\varphi\right) T_{s}
\end{gathered}
$$

Due to the symmetry of the ac inductor current, $i_{L a c}\left(t_{0}\right)=-i_{L a c}\left(t_{2}\right)$.So $i_{L a c}\left(t_{0}\right)$ can be derived,

$$
i_{\text {Lac }}\left(t_{0}\right)=-\frac{V_{\text {in }}+3 n V_{\text {out }} \cdot(4 \varphi-1)}{4 L_{a c}} T_{s}
$$

The average current of ac inductor $L_{a c}$ in a half period is expressed in (6).

$$
\begin{aligned}
\bar{I} & =\left[i_{L a c}\left(t_{0}\right)+i_{L a c}\left(t_{1}\right)\right] \cdot \varphi+\left[i_{L a c}\left(t_{1}\right)+i_{L a c}\left(t_{2}\right)\right] \cdot\left(\frac{1}{2}-\varphi\right) \\
& =\frac{3 n V_{o u t}}{L_{a c}} \varphi(1-2 \varphi) T_{s}
\end{aligned}
$$

Hence, the PPDAB converter's steady-state power equation can be calculated,

$$
P=V_{\text {in }} \cdot \bar{I}=\frac{3 n V_{\text {in }} V_{\text {out }}}{f_{s} L_{a c}} \varphi(1-2 \varphi)
$$

Assume the load $Z_{\text {load }}$ is fixed, the voltage gain can be derived as (8).

$$
\frac{V_{\text {out }}}{V_{\text {in }}}=\frac{3 n Z_{\text {load }}}{f_{s} L_{a c}} \varphi(1-2 \varphi)
$$

Compared to the DAB converter, the PPDAB converter has the following advantages:

- The voltage gain is proportional to the number of paralleled modules.

- The ac current balancing between the parallel modules is inherently ensured by the series connection of the windings on the HV side.

- In addition to single-phase-shift (SPS), the PPDAB converter can be regulated by adding phase shifts among the parallel modules.

\section{INTEGRATED THREE-PHASE HIGH-FREQUENCY TRANSFORMER}

\section{A. Integrated three-phase transformer}

As shown in Fig. 1, the three-phase transformer is a key component to achieve galvanic isolation and voltage converting. In order to improve the performance of the PPDAB converter, a newly integrated three-phase transformer is proposed. The structure is shown in Fig. 3(a) and the equivalent circuit is depicted in Fig. 3(b). The dash lines in Fig. 3(b) means the coupling between the windings. The coils of the HV side, winding-P are wound around the center leg. In addition, the coils of the three parallel modules, winding- $\mathrm{A}$, winding- $\mathrm{B}$, winding- $\mathrm{C}$ are wound around three outer legs, respectively. The cross-sectional area of the center leg is equal to the total area of the three outer legs to ensure the same flux density along the magnetic paths. 


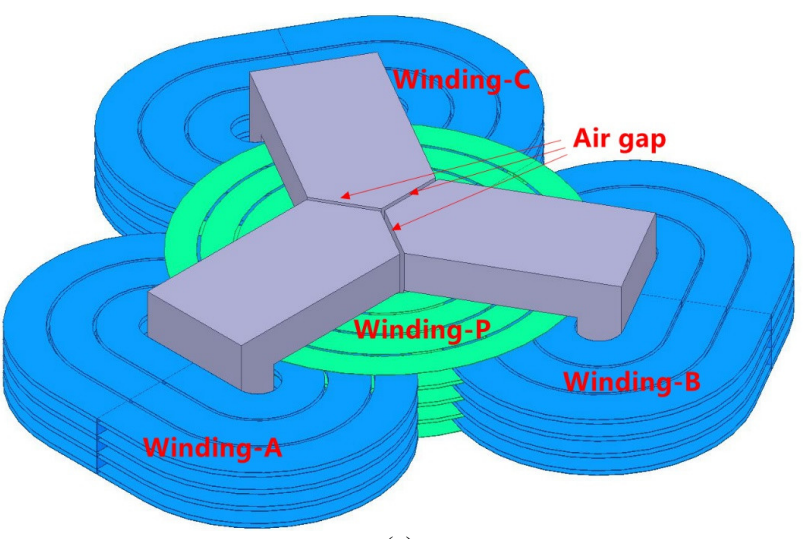

(a)

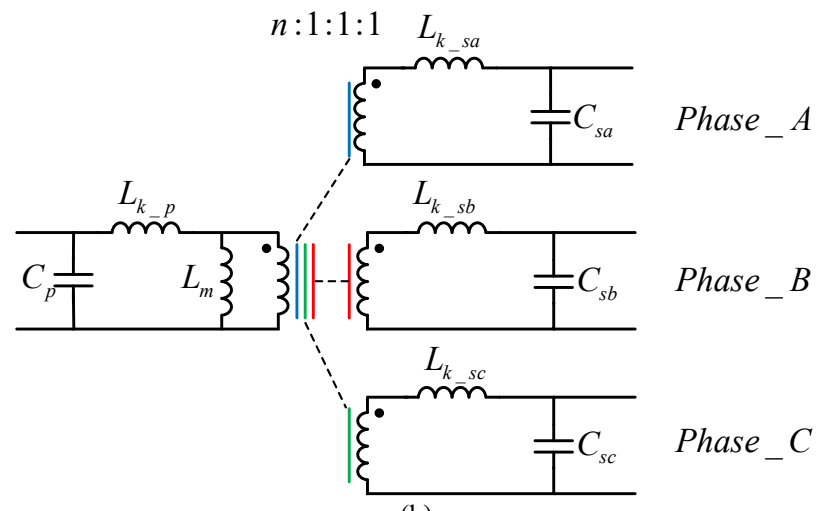

(b)

Fig. 3. Three-phase integrated transformer and ac inductors. (a) configuration of the integrated three-phase transformer, and (b) the equivalent circuit of the integrated three-phase transformer

\section{B. Analysis on ac current balancing}

The reluctance model of the proposed integrated threephase transformer is shown in Fig. 4. Where $F=N I$ is the magneto motive force (MMF), $N$ is the number of turns in the coil and $I$ is the current through the circuit. $\mathscr{R}=l /(\mu A)$, where $l$ is the length of flux path, $\mu$ is the permeability of the material and $A$ is the cross-sectional area. Due to the symmetrical structure, the following assumptions are made:

- The reluctances of three outer legs are the same.

Define: $\mathscr{R}_{A}=\mathscr{R}_{B}=\mathscr{R}_{C}=\mathscr{R}_{S}$

- The reluctances between two arbitrary legs are the same. These reluctances are relative to the thickness of the air gap.

Define: $\mathscr{R}_{A B}=\mathscr{R}_{A C}=\mathscr{R}_{B C}=\mathscr{R}_{S S}$

As shown in Fig. 4, the reluctance model of the center leg is split into three parts. Combine Ampere's Circuital Law, (9) can be obtained.

$$
\left\{\begin{array}{l}
\phi_{A}=\frac{N_{A} I_{A}}{3 R_{P}+R_{S}}-\frac{N_{P} I_{P}}{3 R_{P}+R_{S}}+\frac{\left(2 N_{A} I_{A}-N_{B} I_{B}-N_{C} I_{C}\right) \cdot 9 R_{P}{ }^{2}}{\left(3 R_{P}+R_{S}\right)\left(9 R_{P} R_{S}+6 R_{P} R_{S S}+2 R_{S} R_{S S}\right)} \\
\phi_{B}=\frac{N_{B} I_{B}}{3 R_{P}+R_{S}}-\frac{N_{P} I_{P}}{3 R_{P}+R_{S}}+\frac{\left(2 N_{B} I_{B}-N_{A} I_{A}-N_{C} I_{C}\right) \cdot 9 R_{P}{ }^{2}}{\left(3 R_{P}+R_{S}\right)\left(9 R_{P} R_{S}+6 R_{P} R_{S S}+2 R_{S} R_{S S}\right)} \\
\phi_{C}=\frac{N_{C} I_{C}}{3 R_{P}+R_{S}}-\frac{N_{P} I_{P}}{3 R_{P}+R_{S}}+\frac{\left(2 N_{C} I_{C}-N_{A} I_{A}-N_{B} I_{B}\right) \cdot 9 R_{P}{ }^{2}}{\left(3 R_{P}+R_{S}\right)\left(9 R_{P} R_{S}+6 R_{P} R_{S S}+2 R_{S} R_{S S}\right)} \\
\phi_{P}=\frac{N_{A} I_{A}+N_{B} I_{B}+N_{C} I_{C}}{3 R_{P}+R_{S}}-\frac{3 N_{P} I_{P}}{3 R_{P}+R_{S}}
\end{array}\right.
$$

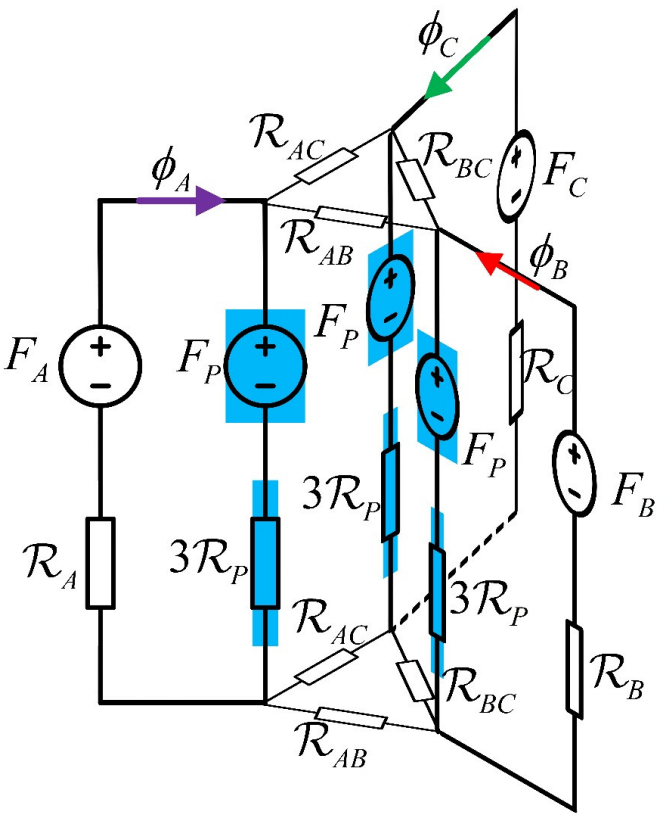

Fig. 4. Reluctance model

where $\phi_{P}$ is the total flux in the center leg, and $\phi_{A}, \phi_{B}, \phi_{C}$ are the flux in the three outer legs, respectively.

Due to the symmetrical structure and the same switching patterns of the three parallel modules, the following equation can be derived:

$$
\phi_{A}=\phi_{B}=\phi_{C}=\frac{1}{3} \phi_{p}
$$

Combining (9) and (10), (11) can be obtained.

$$
N_{A} I_{A}=N_{B} I_{B}=N_{C} I_{C}
$$

Therefore, it can be seen that when the numbers of turns of winding-A, winding-B, winding-C are kept the same, the ac currents in each parallel modules will be balanced.

\section{Leakage inductance}

By placing the primary and secondary windings on the center leg and outer legs, respectively, the leakage inductance of the transformer can be increased. In order to ensure the leakage inductor is large enough to serve as the ac inductor in the PPDAB converter, the finite element analysis (FEA) is used to design the windings structure of the transformer.

\section{Comparison between the integrated three-phase transformer and discrete three-phase transformer}

Winding loss is frequency-dependent due to the skin effect and proximity effect. Both effects cause the current unevenly distributed in the cross section of the conductor and cause a high winding resistance at high frequency.

The windings of the integrated three-phase transformer and the discrete three-phase transformer are depicted in Fig. 5.

With the FEA method, the winding loss can be simulated. In order to make a fair comparison, the parameters of the two three-phase transformers are listed in Table I and the simulation results are listed in Table II. From this comparison, we can conclude that the proposed integrated three-phase transformer has a lower winding loss. 


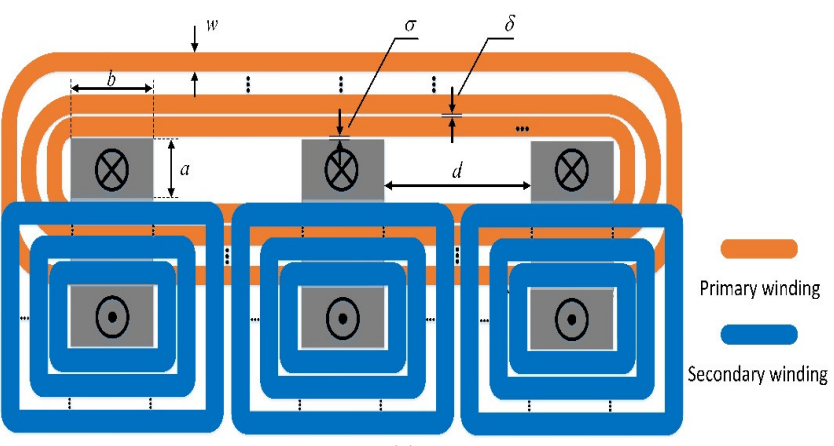

(a)

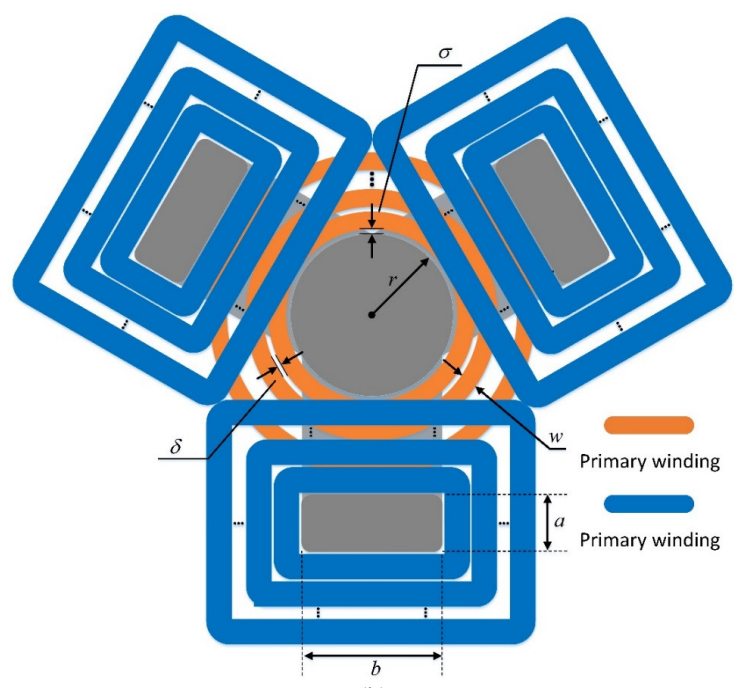

(b)

Fig. 5. Compassion of two three-phase transformer structures. (a) discrete and (b) integrated.

TABLE I

PARAMETERS OF THE TWO THREE-PHASE TRANSFORMERS

\begin{tabular}{|c|c|c|}
\hline Parameter & Value & Description \\
\hline & U-37.5-8.525-18.5 & Core dimensions(integrated) \\
\hline & U-32.6-8.525-18.5 & Core dimensions(discrete) \\
\hline$f / k H z$ & 500 & Switching frequency \\
\hline$w_{H V} / m m$ & 6 & Winding width on the HV side \\
\hline$w_{L V} / m m$ & 4.25 & Winding width on the LV side \\
\hline$h$ & $2 o z(0.07 \mathrm{~mm})$ & Winding thickness \\
\hline$\delta / \mathrm{mm}$ & 0.5 & $\begin{array}{l}\text { Distance between any two } \\
\text { arbitrary turns }\end{array}$ \\
\hline$\sigma / m m$ & 0.254 & $\begin{array}{c}\text { Space between the core and } \\
\text { turns }\end{array}$ \\
\hline $\operatorname{Tr}-P, A, B, C$ & $8: 3: 3: 3$ & Number of turns \\
\hline$m_{H V}$ & 2 & $\begin{array}{l}\text { Number of layers of windings } \\
\text { in HV side (in series) }\end{array}$ \\
\hline$m_{L V}$ & 2 & $\begin{array}{l}\text { Number of layers of windings } \\
\text { in LV side (in parallel) }\end{array}$ \\
\hline$I_{H V} / A$ & 3 & Current amplitude of HV side \\
\hline$I_{L V} / A$ & 8 & Current amplitude of LV side \\
\hline
\end{tabular}

TABLE II

SiMULATION RESULT OF THE WINDING LOSS

\begin{tabular}{lcc}
\hline & $\begin{array}{c}\text { Integrated three- } \\
\text { phase transformer }\end{array}$ & $\begin{array}{c}\text { Discrete three-phase } \\
\text { transformer }\end{array}$ \\
\hline Winding loss / W & 1.9125 & 2.5065
\end{tabular}

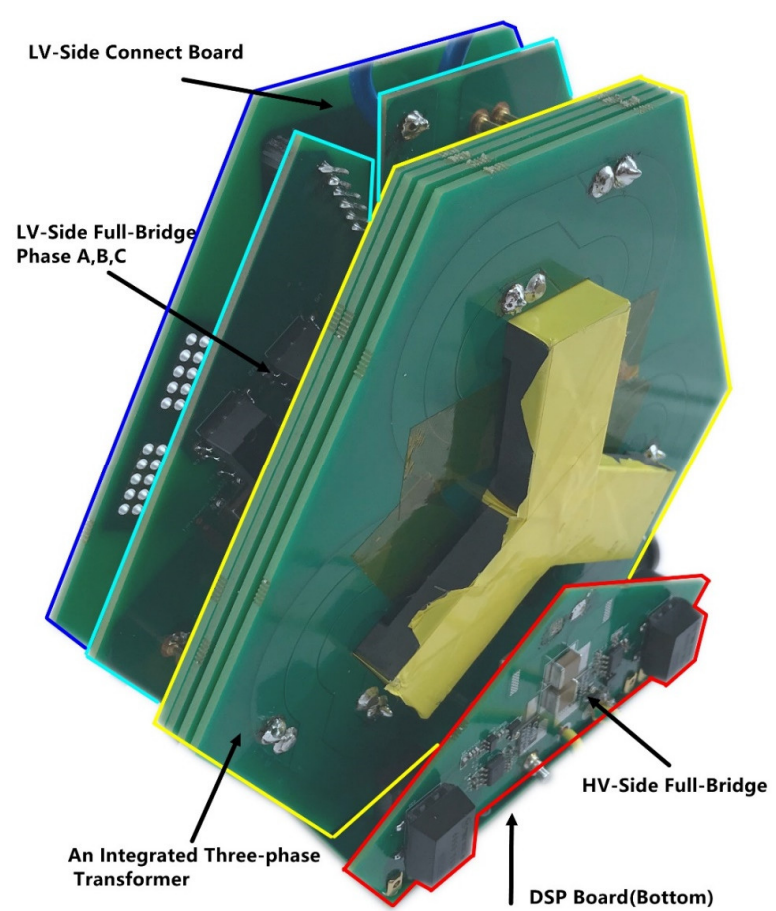

Fig. 6. Picture of the PPDAB converter hardware prototype

TABLE III

SPECIFICATIONS OF THE PROTOTYPE

\begin{tabular}{|c|c|c|}
\hline Parameter & Value & Description \\
\hline$V_{\text {in }}$ nom & $400 \mathrm{~V}$ & Nominal DC input voltage \\
\hline$V_{\text {out_nom }}$ & $50 \mathrm{~V}$ & Nominal DC output voltage \\
\hline$P_{r}$ & $1 \mathrm{~kW}$ & Rated power \\
\hline$f_{s}$ & $500 \mathrm{kHz}$ & Switching frequency \\
\hline $\operatorname{Tr}-P, A, B, C$ & $8: 3: 3: 3$ & Number of turns \\
\hline Transformer & ML91S & Material \\
\hline Transformer & U-37.5-12.2-18.5 & Core dimensions \\
\hline$L_{a c}$ & $22.0213 \mu H$ & $\begin{array}{l}\text { Total leakage inductance re- } \\
\text { ferred to the HV side }\end{array}$ \\
\hline$\varphi$ & $10 \%$ & $\begin{array}{c}\text { Phase shift between the HV } \\
\text { side and LV side }\end{array}$ \\
\hline $\begin{array}{l}\text { Digital Con- } \\
\text { troller }\end{array}$ & TMS320F28379D & Digital signal processing \\
\hline $\begin{array}{l}\text { Power semi- } \\
\text { conductor }\end{array}$ & GS66504B & Switches on the HV side \\
\hline $\begin{array}{l}\text { Power semi- } \\
\text { conductor }\end{array}$ & EPC2021 & Switches on the LV side \\
\hline
\end{tabular}

\section{EXPERIMENTAL RESULTS}

In order to verify the proposed converter and its associated magnetic integration, a $1 \mathrm{~kW}$ three-phase PPDAB converter with the newly integrated three-phase transformers was constructed and tested. The photo of the built prototype is shown in Fig. 6 and the prototype specifications are summarized in Table III.

Two winding techniques i.e. wire-wound and print circuit board (PCB) winding are tested and compared for the proposed magnetic structure. Fig.7 shows the wire-wound transformer and its windings arrangement, and Fig.8 shows the solution with PCB windings and its windings arrangement. The transformer in Fig. 8 has a lower leakage inductance due to the windings interleaving. 


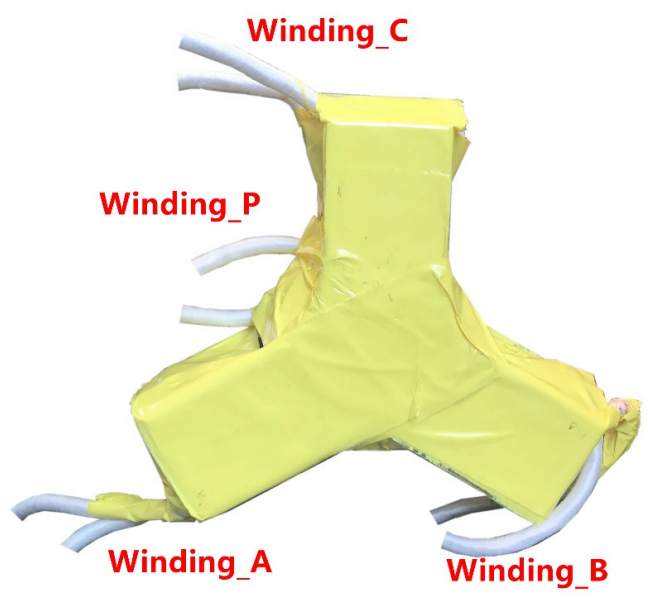

(a)

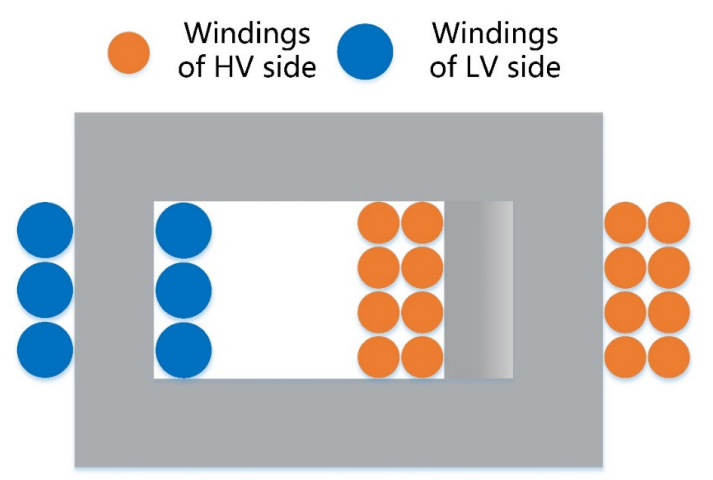

(b)

Fig. 7. Wire-wound transformer. (a) wire-wound transformer and (b) winding arrangement

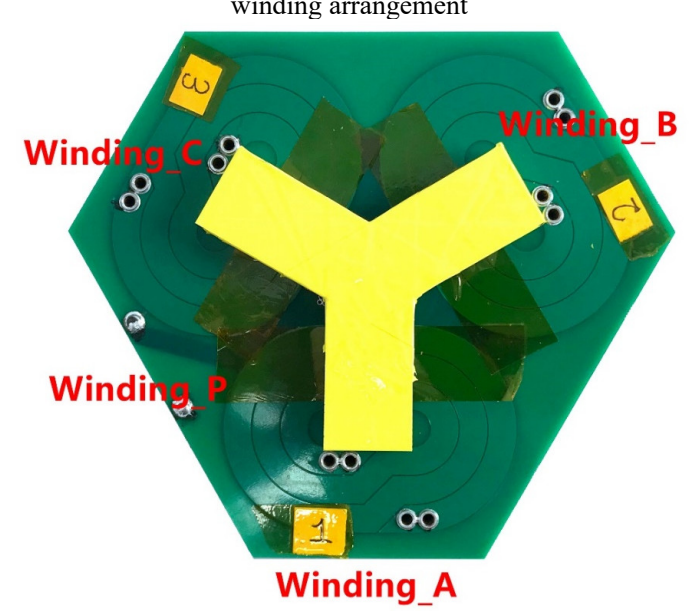

(a)

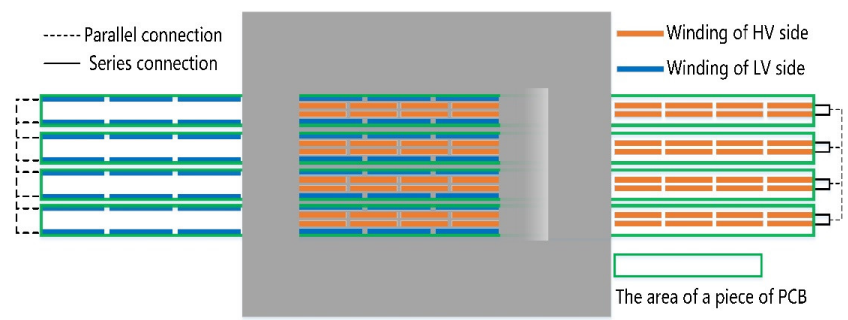

(b)

Fig. 8. Planar transformer with PCB windings. (a) planar transformer and (b) winding arrangement

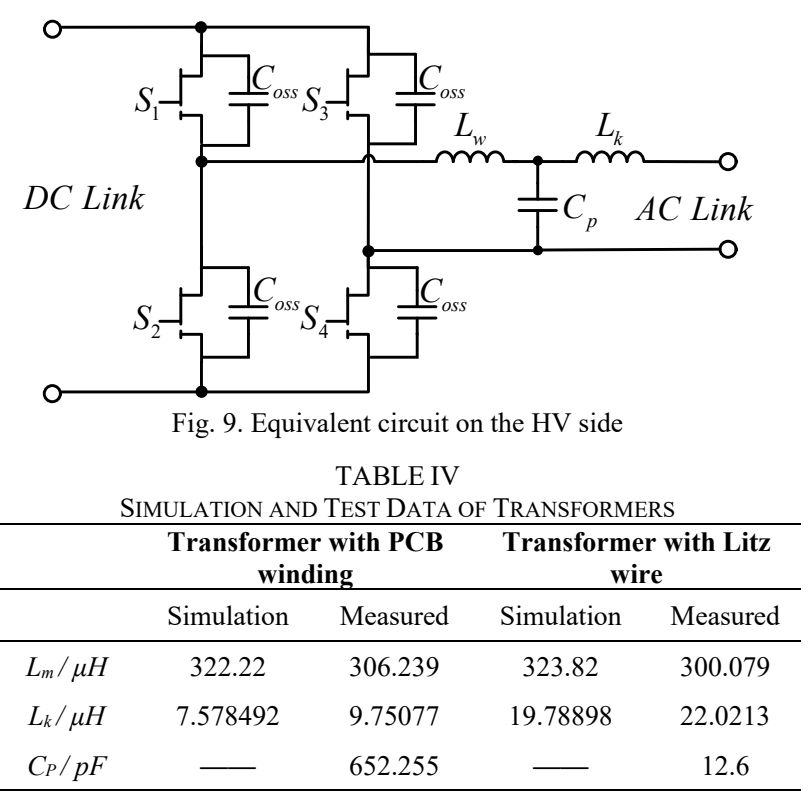

However, the large surface area of the PCB windings increases the winding parasitic capacitance. The simulation and measured results of the transformers with these two different windings are listed in Table IV, where $L_{m}$ is the magnetizing inductance of the windings on the HV side, $L_{k}$ is the total leakage inductance referred to the HV side and $C_{p}$ is the parasitic capacitance of the windings on the $\mathrm{HV}$ side. The equivalent circuit of the HV side is shown in Fig. 9. $L_{w}$ is the inductance of a wire which is placed in series in the circuit path for ease on current probing.

The waveform of the three-phase PPDAB converter with the planar transformer with PCB windings working at $200 \mathrm{kHz}$ is shown in Fig. 10. The waveform is labeled according to Fig. 1.

It shows that after S1and S3 turn off, the $L_{w}$ firstly resonates with output capacitance $C_{\text {oss }}$ of the semiconductor devices on the HV side. The resonant frequency $f_{\text {res } 1}$ can be calculated,

$$
f_{\text {res } 1}=\frac{1}{2 \pi \sqrt{L_{w} \cdot C_{o s s}}}
$$

After S2 and S4 turn on, the LCL form by $L_{w}, C_{p}$, and $L_{k}$ results in a high amplitude current resonance and causes higher conduction loss of the primary devices.

The resonant frequency $f_{\text {res } 2}$ can be expressed,

$$
f_{\text {res } 2}=\frac{1}{2 \pi \sqrt{\frac{L_{k} L_{w}}{L_{k}+L_{w}} \cdot C_{p}}}
$$

Finally, the calculation results of the resonant frequency are listed in Table V.

TABLE V

CALCULATiOn RESUlt OF THE RESONANT FREQUENCY

\begin{tabular}{cc}
\hline Parameter & Value \\
\hline$L_{k} / \mu H$ & 9.75077 \\
$C_{P} / p F$ & 652.255 \\
$L_{w} / n H$ & 95.1 \\
$C_{\text {oss }} / p F$ & 80 \\
$f_{\text {res } 1} / M H z$ & 57.7 \\
$f_{\text {res } 2} / M H z$ & 20.306 \\
\hline
\end{tabular}




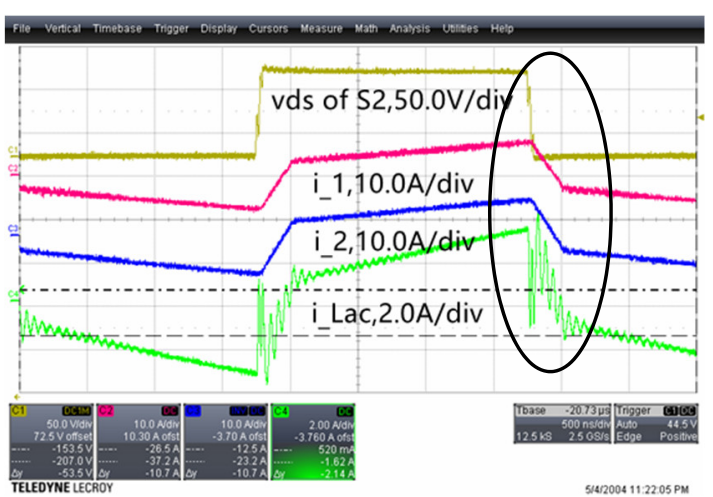

(a)

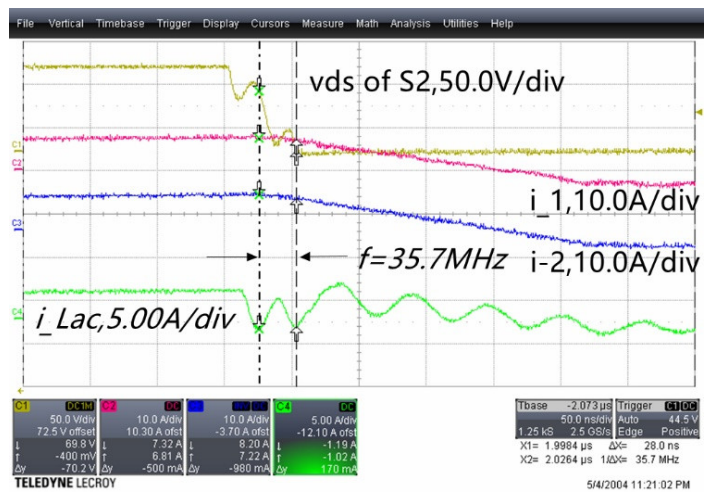

(b)

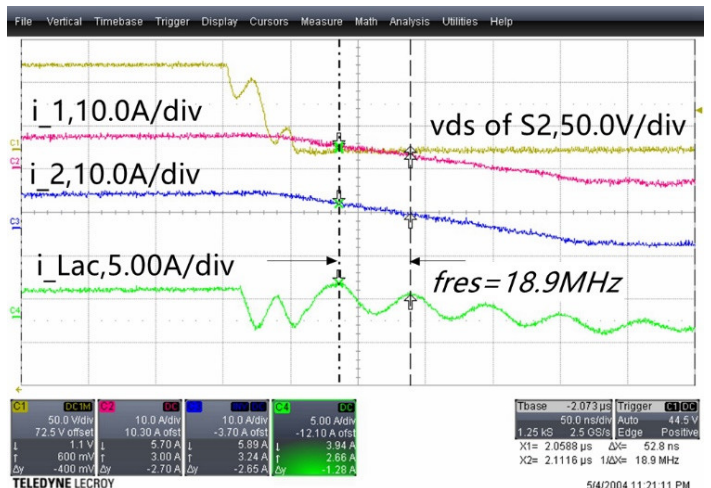

(c)

Fig. 10. (a)The working waveform of the PPDAB converter with a planar transformer with PCB windings. (b)zoom in the resonant rings and measure the LC resonant frequency (c)zoom in the resonant rings and measure the LCL resonant frequency

It can be seen that the measured $f_{\text {res } 2}$ matches the calculated result, which verifies the resonance is because of LCL resonance of $C_{p}, L_{k}$, and $L_{w}$. However, there are still errors on the calculated $f_{\text {res } 1}$ and it will be studied further in the future work.

Therefore, in the final test, a wire-wound transformer shown in Fig. 7(a) is employed in the prototype. Fig. 11 provides the thermal picture of the proposed three-phase PPDAB converter working at $1 \mathrm{~kW}, 400 \mathrm{~V} / 50 \mathrm{~V}$. The temperature of the devices in the $\mathrm{HV}$ side reaches $72^{\circ} \mathrm{C}$, which is still within the safe temperature range. Fig. 12 gives the experimental waveforms of the proposed three-phase PPDAB converter operating at $1 \mathrm{~kW}, 400 \mathrm{~V} / 50 \mathrm{~V}$. The waveforms are labeled according to Fig. 1. The proposed three-phase PPDAB converter has an efficiency of $96.72 \%$ at the rated power.

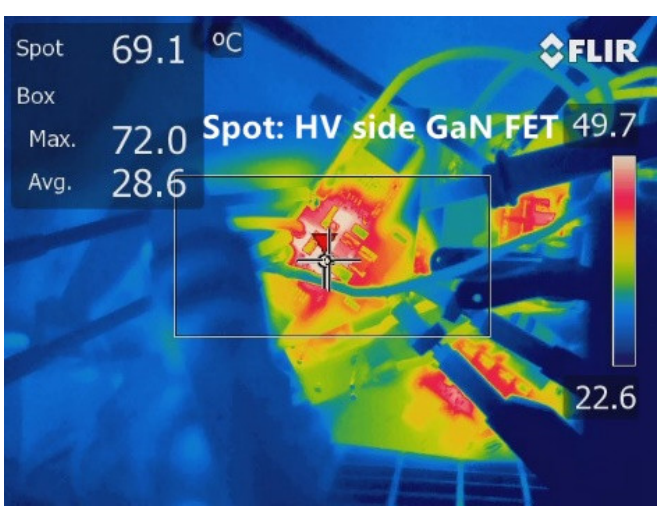

Fig. 11. Thermal image

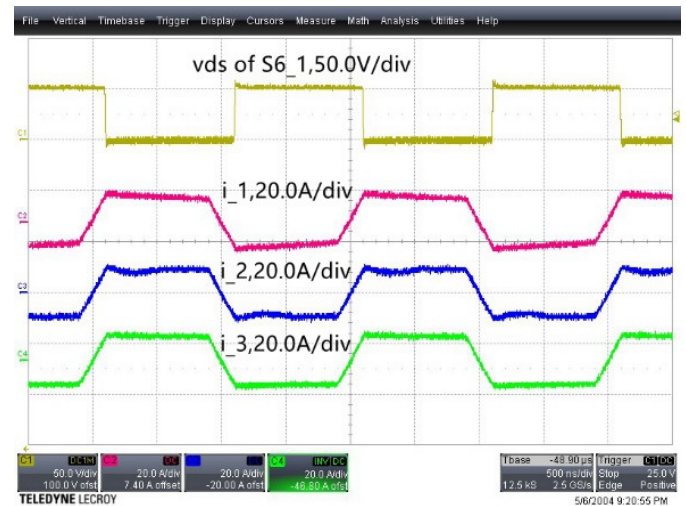

(a)

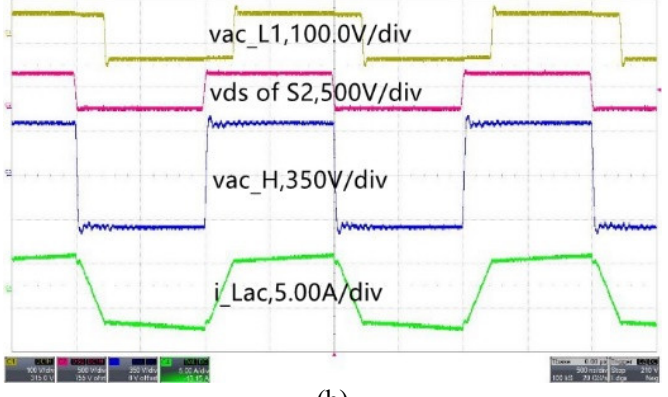

(b)

Fig. 12. Measured waveforms at the rated power

\section{CONCLUSIONS}

In this paper, a new integrated three-phase transformer is proposed for the PPDAB converter. Compared to the discrete three-phase transformer, the proposed integrated one has a lower winding loss. In order to ensure the leakage inductor is large enough to serve as the ac inductor in the PPDAB converter, the FEA method is used to design the windings structure of the proposed transformer. From the experimental results, we are able to verify the theoretical analysis and can see the three high-frequency ac currents in the paralleled branches are well balanced. Finally, the efficiency is $96.72 \%$ at the rated power. Modeling the leakage inductance of the proposed integrated three-phase transformer and optimizing the PCB windings to reduce the parasitic capacitance will be carried out in the future work. 


\section{REFERENCES}

[1] J. Cao and A. Emadi, "A New Battery/UltraCapacitor Hybrid Energy Storage System for Electric, Hybrid, and PlugIn Hybrid Electric Vehicles," IEEE Transactions on Power Electronics, vol. 27, no. 1, pp. 122-132, Jan. 2012.

[2] J. Shi, W. Gou, H. Yuan, T. Zhao and A. Q. Huang, "Research on voltage and power balance control for cascaded modular solid-state transformer," IEEE Transactions on Power Electronics, vol. 26, no. 4, pp. 1154-1166, April 2011.

[3] Z. Zhang, O. C. Thomsen and M. A. E. Andersen, "Optimal Design of a Push-Pull-Forward Half-Bridge (PPFHB) Bidirectional DC-DC Converter With Variable Input Voltage," IEEE Transactions on Industrial Electronics, vol. 59, no. 7, pp. 2761-2771, July 2012.

[4] Z. Zhang, K. Tomas-Manez, Y. Xiao and M. A. E. Andersen, "High voltage gain dual active bridge converter with an extended operation range for renewable energy systems," 2018 IEEE Applied Power Electronics Conference and Exposition (APEC), San Antonio, TX, 2018, pp. 1865-1870.

[5] R. Zhu, G. De Carne, F. Deng and M. Liserre, "Integration of Large Photovoltaic and Wind System by Means of Smart Transformer," IEEE Transactions on Industrial Electronics, vol. 64, no. 11, pp. 8928-8938, Nov. 2017.

[6] B. Zhao, Q. Song, W. Liu and Y. Sun, "Overview of DualActive-Bridge Isolated Bidirectional DC-DC Converter for High-Frequency-Link Power-Conversion System," IEEE Transactions on Power Electronics, vol. 29, no. 8, pp. 40914106, Aug. 2014.

[7] Y. Xuan, X. Yang, W. Chen, T. Liu and X. Hao, "A Novel NPC Dual-active-bridge Converter with Blocking Capacitor for Energy Storage System," IEEE Transactions on Power Electronics.

[8] L. F. Costa, F. Hoffmann, G. Buticchi and M. Liserre, "Comparative Analysis of Multiple Active Bridge Converters Configurations in Modular Smart Transformer," IEEE Transactions on Industrial Electronics, vol. 66, no. 1, pp. 191-202, Jan. 2019.

[9] Cielo J R, Hoffman Jr H S. Combined transformer and inductor device: U.S. Patent 3,694,726[P]. 1972-9-26.

[10] S. Ćuk, "A new zero-ripple switching dc-to-dc converter and integrated magnetics," 1980 IEEE Power Electronics Specialists Conference, Atlanta, Georgia, USA, 1980, pp. 12-32.

[11] G. E. Bloom, "New multi-chambered power magnetics concepts," IEEE Transactions on Magnetics, vol. 34, no. 4, pp. 1342-1344, July 1998.

[12] J. S. Ngoua Teu Magambo et al., "Planar Magnetic Components in More Electric Aircraft: Review of Technology and Key Parameters for DC-DC Power Electronic Converter," IEEE Transactions on Transportation Electrification, vol. 3, no. 4, pp. 831-842, Dec. 2017.

[13] Z. Ouyang and M. A. E. Andersen, "Overview of Planar Magnetic Technology_Fundamental Properties," IEEE Transactions on Power Electronics, vol. 29, no. 9, pp. 48884900, Sept. 2014.

[14] C. Fei, F. C. Lee and Q. Li, "High-Efficiency High-PowerDensity LLC Converter With an Integrated Planar Matrix Transformer for High-Output Current Applications," IEEE Transactions on Industrial Electronics, vol. 64, no. 11, pp. 9072-9082, Nov. 2017.

[15] B. Li, Q. Li and F. C. Lee, "A WBG based three phase 12.5 $\mathrm{kW} 500 \mathrm{kHz}$ CLLC resonant converter with integrated PCB winding transformer," 2018 IEEE Applied Power Electronics Conference and Exposition (APEC), San Antonio, TX, 2018, pp. 469-475. 